\title{
ANALYSIS OF THE MAIN BODY BEHAVIOUR OF NON-POINT SOURCE POLLUTION CONTROL BASED ON MULTIMODAL GAME MODEL
}

\begin{abstract}
The issue of agricultural non-point source pollution has attracted the attention of the state and the masse. In the non-point source pollution control organizations which composed of the governments, farmers and fertiliser sellers, due to the characteristics of rational economic body, the phenomenon of "market failure" and "government failure" may occur in the process of non-point source pollution control. In this paper, the author applies game theory to analyse the main behaviour characteristics of the three main bodies, and constructs the incomplete information dynamic game model that the government, farmers and fertiliser sellers participate in. According to the results of the equilibrium solution of the Haysani Axiom model, it is found that the decisions made by the three bodies of the government, the fertiliser seller and the farmer in the behaviour choice stage have a great influence on the behaviour choice of the other two bodies, and the process of each strategy choice by the three bodies is a dynamic game process of the three bodies. Finally, according to the main influencing factors reflected in the equilibrium solution, proposed the related non-point source pollution control countermeasure suggestion to the government main body.
\end{abstract}

Keywords: non-point source pollution, game theory, pollution control policy

\section{Introduction}

Agricultural development has always played a vital role in the historical stage of mankind. Whether it is the promotion of the national economy of individual countries or the long-term stable development of the entire human society, agricultural development plays a decisive role. The essence of agricultural non-point source pollution is the problem of environmental control. The treatment of agricultural non-point source pollution is related to the stability and development of the country. In order to promote the increase of agricultural production and the increase of farmers' income in China, the use of agricultural chemicals such as chemical fertilisers has become the main way to help farmers maximise their production returns. Excessive use of agricultural chemicals such as chemical fertilisers has led to more serious agricultural non-point source pollution, the quality and safety of agricultural products also severely affected threatening people's lives and health, and hindering the sustainable development of agriculture [1-5].

According to the existing research data, the non-point source pollution of chemical fertiliser is greatly affected by natural factors, the pollution range is wide and scattered, the pollution responsibility is difficult to identify, and the difficulty of chemical fertiliser

\footnotetext{
${ }^{1}$ College of Economy and Management, Northeast Forestry University, Harbin 150040, Heilongjiang, China, email: 1x67898892@126.com, ORCID: XL 0000-0002-6383-8965, JS 0000-0002-9576-5529

*Corresponding author: hello_o_o@nefu.edu.cn
} 
non-point source pollution control is increased. Many scholars also put forward from different disciplines and the management ideas of agricultural non-point source pollution, such as legal control, economic incentives, etc., but these studies are mainly aimed at governance control measures for a single subject, with narrow research fields and strong pertinence [6-8]. There are still problems such as absence of laws, lack of control institutions and backward management and control modes in China's chemical fertilisers. So, the non-point source pollution of fertilisers is still out of control [9-11]. The government, farmers and fertiliser sellers are three main behaviour is the important factors that affect fertiliser effect of non-point source pollution control, because each body is a rational economic body, this causes fertiliser non-point source pollution treatment of "market failure" and "government failure" phenomenon. Therefore, based on the above background, a game model in which multi-party governance entities participate together is constructed, and the game behaviour analysis of its subject behaviour is carried out to seek the equilibrium state of behaviour choice among various subjects in the management of non-point source pollution of chemical fertilisers, in order to effectively curb the increasingly serious non-point source pollution puts forward appropriate countermeasures.

\section{Current situation of chemical fertiliser application}

In order to pursue the yield and quality of agricultural products, farmers all over the world have adopted different degrees of chemical fertiliser application behaviour in the process of agricultural production. According to the latest comprehensive available data, the total amount of chemical fertiliser application in the world reached $0.192 \mathrm{Pg}$ (192 $\mathrm{Tg}=1.92 \cdot 10^{8}$ tonnes) in 2017. In this paper, the top 10 countries with cultivated land area in the world in 2017 were selected to carry out the research, and the cultivated land area and fertiliser application rate in the United States, India, Russia, China, Brazil, Argentina, Canada, Nigeria, Ukraine and Pakistan in 2017 were calculated as shown in Table 1.

Table 1

Cultivated land area and fertiliser application rate in different countries in 2017 [12-14]

\begin{tabular}{|c|c|c|c|}
\hline Country & $\begin{array}{c}\text { Cultivated land area } \\
{\left[\mathbf{1 0}^{\mathbf{4}} \mathbf{~ k m}^{\mathbf{2}}\right]}\end{array}$ & $\begin{array}{c}\text { Application amount of } \\
\text { chemical fertiliser } \\
{[\mathbf{1 0} \text { tonnes }]}\end{array}$ & $\begin{array}{c}\text { Application rate per unit } \\
\text { cultivated area } \\
{[\mathbf{k g} / \mathbf{h a}]}\end{array}$ \\
\hline United States & 157.74 & 2014.56 & 127.71 \\
\hline India & 156.42 & 2659.09 & 170.00 \\
\hline Russia & 121.65 & 247.29 & 20.33 \\
\hline China & 119.49 & 5859.41 & 490.37 \\
\hline Brazil & 55.76 & 1538.66 & 275.94 \\
\hline Argentina & 39.20 & 165.85 & 42.31 \\
\hline Canada & 38.51 & 392.10 & 101.82 \\
\hline Nigeria & 34.00 & 73.39 & 61.59 \\
\hline Ukraine & 32.77 & 202.81 & 152.48 \\
\hline Pakistan & 31.21 & 475.89 & \\
\hline
\end{tabular}

In this paper, the application rate of chemical fertiliser per unit cultivated land area in various countries is calculated by the data in Table 1 , and the application intensity of chemical fertiliser per unit cultivated land area in various countries is compared. The results of chemical fertiliser application per unit cultivated land area in 2017 are shown 
in Figure 1. From Figure 1, it can be seen that the application rate of chemical fertiliser per unit cultivated land area in China is the first in the world, which is much higher than that in other countries, as high as $490.37 \mathrm{~kg} / \mathrm{ha}, 1.78$ times as much as that in second Argentina, and 24.12 times as much as the tenth unit cultivated land area in Russia. Thus it can be seen that the task of chemical fertiliser non-point source pollution control in China is a long way to go, and it is still necessary to find effective non-point source pollution control methods.

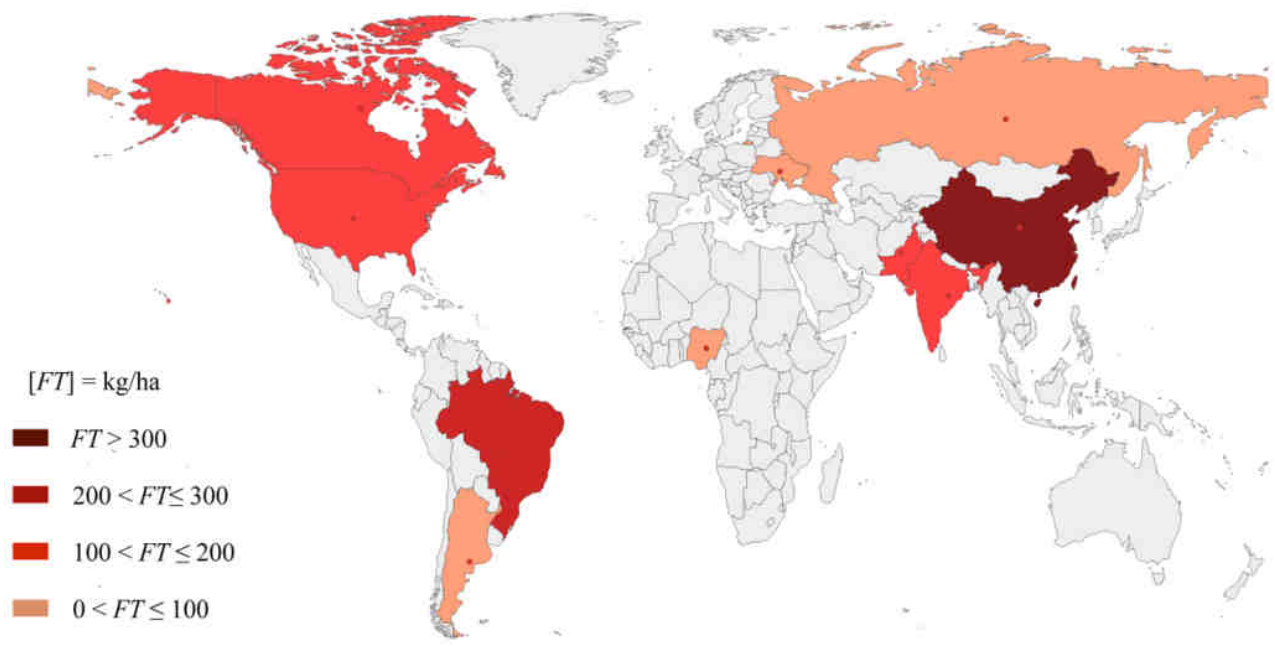

Fig. 1. Fertiliser application rate per unit cultivated area of top ten countries in 2017. FT represents amount of chemical fertiliser used per unit of arable land

The pressure of increasing grain production, the low basic land capacity of cultivated land, the high intensity of cultivated land use and the small scale of farmers' production lead farmers to rely on chemical fertiliser to achieve the effect of maintaining quality and quantity to a certain extent. According to data released by the Ministry of Agriculture of China, fertiliser use in China increased first and then decreased from 2013 to 2019, as shown in Figure 2. In 2019, the application rate of chemical fertiliser was the lowest in nearly seven years, and the amount of chemical fertiliser applied in China was effective at the beginning of controlling chemical fertiliser application, but according to the amount of chemical fertiliser applied in 2019, the amount of chemical fertiliser applied per unit cultivated land area in China was still as high as $436.48 \mathrm{~kg} / \mathrm{ha}$, and the amount of chemical fertiliser applied in China was much higher than that in other countries. In this paper, the main body behaviour of chemical fertiliser non-point source pollution control is deeply studied, and a new way to control chemical fertiliser non-point source pollution in China is explored, which provides certain theoretical support for reducing the amount of chemical fertiliser application in China and promoting the sustainable production of agriculture in China. 


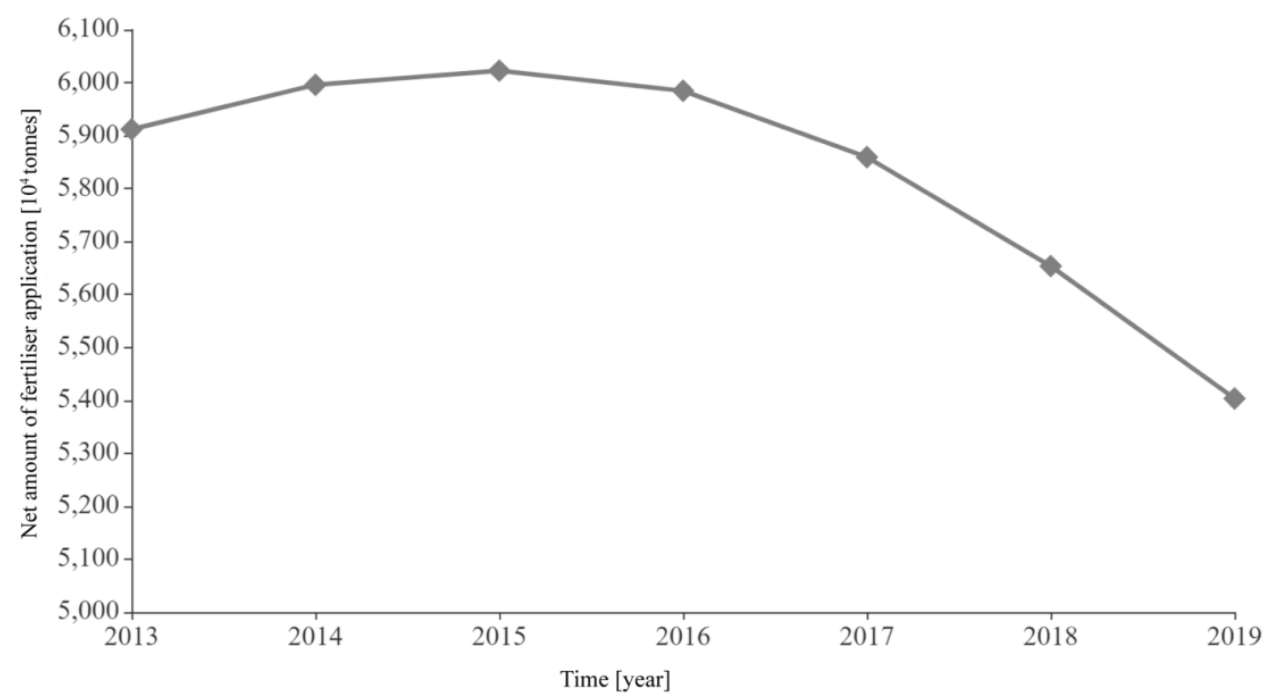

Fig. 2. Change of net fertiliser application in China from 2013 to 2019

\section{Analysis of the behaviour of the three parties}

\section{Government subject behaviour}

In chemical fertiliser non-point source pollution control, the government is one of the main body of its governance organization, its main responsibility is in view of the pollution control policy and policy implementation supervision, its main behaviour includes creating an overall work plan and framework, macro policy, put forward countermeasures for pollution control, and to establish laws and regulations and governance system, at the same time for sellers other related groups such as farmers, agricultural materials proper supervision and management and provide correct guidance and technical support [15]. China's agricultural non-point source pollution problem is coordinated by the central government and governments to complete the corresponding governance work. The central government is mainly responsible for formulating macroeconomic policies in line with the national agricultural non-point source pollution control situation, and the government is mainly responsible for the agricultural aspects of the region. The implementation of the source pollution control policy proposes more specific and targeted governance measures to improve the agricultural production environment in the region. In the process of controlling non-point source pollution of chemical fertilisers, local governments have the following characteristics:

(1) The behaviour characteristics of short-term goals. Chinese local government is in the performance appraisal system. If the local government's supervision responsibility is derelict, it will bring negative impact on the performance of relevant government officials, and also bring negative externality to the regional economic development. If the provincial government takes action against the pollution situation, it may touch the economic interests of other interest groups and reduce the local financial revenue, which will also have a negative impact on the performance evaluation of the local government. Therefore, when 
the control goal of chemical fertiliser non-point source pollution conflicts with other objectives, the government must weigh the decision in order to maximise the balanced interests.

(2) Characteristics of rent-seeking behaviour. The rent-seeking behaviour of local government in the treatment of non-point source pollution of chemical fertiliser is divided into pre-rent-seeking and post-rent-seeking. The former directly through the pollution control of different channels and relevant policies to obtain the corresponding funds, the latter refers to the use of chemical fertiliser non-point source pollution control system is not perfect loopholes to obtain non-governance benefits. Therefore, the rent-seeking behaviour of the local government has a serious impact on the treatment of chemical fertiliser non-point source pollution.

(3) The characteristics of "hitchhiking" behaviour of local governments. According to the guiding ideology of the central government, the local governments have issued relevant laws, regulations and policies according to the characteristics and present situation of their respective regions [16]. However, because the laws, regulations and policies with regional characteristics have increased the cost of institutional change, it is difficult for local governments to achieve interregional linkage to control chemical fertiliser non-point source pollution and reduce the enthusiasm for interregional control. As a result, local governments have "hitchhiked" the innovation system in other regions.

\section{Farmers' main behaviour}

Farmers are not only the direct main body in agricultural production, but also the most direct interest body in chemical fertiliser non-point source pollution control organization. Through the field investigation, it is found that most farmers have realised the negative impact of chemical fertiliser non-point source pollution on the agricultural production environment, but very few actions have been taken to control the pollution, which is closely related to the economic interests of farmers concerned with pollution control [6]. At present, under the limitation of agricultural production technology and production costs and benefits, farmers still need to be driven by certain interests to take action to control chemical fertiliser non-point source pollution.

Farmers' own conditions, production base, production methods, etc. are not the same, and there are many external factors, which may result in different results when farmers make decision-making behaviours. Regardless of the external influence factors, farmers must first consider their own interests. Therefore, when agricultural production is carried out, farmers have two behavioural choices: environmentally friendly chemical fertiliser application and environmental pollution type fertiliser application. This paper assumes that the choice of environmentally friendly fertiliser can increase the selling price of crops, protect the agricultural production environment, and receive government subsidies. Choose environmental pollution fertilisation can increase the output of agricultural products and increase their own economic returns, but it is likely to cause agricultural products. The decline in quality has increased the burden on the agricultural production environment. Under the condition of not considering the influence of other external factors, the game payoff matrix between the farmers and the farmers was analysed by comparing the game payoff matrix of the two farmers under the conditions of complete information, complete non-disclosure and incomplete information [17].

Assume that the existing farmers A and B planting the same crops have the same fertilisation cost per unit crop in the case of environmentally friendly fertiliser application. 
The sales prices of $\mathrm{A}$ and $\mathrm{B}$ are $P_{1}$ and $P_{2}$, respectively, in the same market environment. The sales volume of $\mathrm{A}$ and $\mathrm{B}$ are $Q_{1}$ and $Q_{2}$ respectively. The farmers A and B choose the environmental pollution type fertiliser application, and the fertiliser cost per unit crop is $C>c$. In the following analysis, Option $\mathrm{A}$ is to select an environmentally friendly application of fertiliser, and Option B is to select an environmentally polluting application of fertiliser.

(1) Game analysis of farmers' fertilisation behaviour under the condition of complete information.

Under the condition that the information is completely open, the farmers A and B understand each other's behaviour choices. When both parties choose option A, the incomes of $\mathrm{A}$ and $\mathrm{B}$ are $Q_{1}\left(P_{1}-C\right)$ and $Q_{2}\left(P_{2}-C\right)$ respectively. When A chooses plan A and $\mathrm{B}$ chooses plan $\mathrm{B}$, because the information is completely open. The purchaser knows the details of the production of both parties, the purchaser will tend to choose to purchase a healthier product, and the total demand of the market will not change, resulting in the income of $\mathrm{B}$ is 0 , and the income of $\mathrm{A}$ is $\left(Q_{1}+Q_{2}\right)\left(P_{1}-C\right)$. If $\mathrm{A}$ chooses option $\mathrm{B}$ and $\mathrm{B}$ chooses plan A, the result is reversed. When both Party A and Party B choose Option B, the purchaser refuses to purchase the agricultural products of both parties, so the income is 0 . Table 2 shows the game payoff matrix of farmers A and B under the condition that the information is fully disclosed.

Table 2

Game payoff matrix under full information conditions

\begin{tabular}{|c|c|c|c|}
\hline \multicolumn{2}{|c|}{$\begin{array}{c}\text { Participate in farmers and } \\
\text { options }\end{array}$} & Option A & Party B \\
\cline { 2 - 4 } & Option A & $Q_{1}\left(P_{1}-C\right), Q_{2}\left(P_{2}-C\right)$ & $\left(Q_{1}+Q_{2}\right)\left(P_{1}-C\right), 0$ \\
\cline { 2 - 4 } Party A & Option B & $0,\left(Q_{1}+Q_{2}\right)\left(P_{2}-C\right)$ & 0,0 \\
\cline { 2 - 4 } & &
\end{tabular}

According to the game benefit matrix analysis of party A and party B, Nash equilibrium can be reached when party A and party B choose to apply chemical fertiliser in accordance with the standard, and the diffusion of non-point source pollution of chemical fertiliser can be effectively controlled.

(2) Game analysis of farmer's fertilisation behaviour under the condition of complete non-disclosure of information.

Table 3

Game payoff matrix under completely undisclosed information

\begin{tabular}{|c|c|c|c|}
\hline \multicolumn{2}{|c|}{$\begin{array}{c}\text { Participate in farmers and } \\
\text { options }\end{array}$} & Option A & Party B \\
\cline { 2 - 4 } & Option A & $Q_{1}\left(P_{1}-C\right), Q_{2}\left(P_{2}-C\right)$ & $Q_{1}\left(P_{1}-C\right), Q_{2}\left(P_{2}-c\right)$ \\
\hline \multirow{2}{*}{ Party A } & Option B & $Q_{1}\left(P_{1}-c\right), Q_{2}\left(P_{2}-C\right)$ & $Q_{1}\left(P_{1}-c\right), Q_{2}\left(P_{2}-c\right)$ \\
\cline { 2 - 4 }
\end{tabular}

Suppose that under this condition, farmer A and farmer B do not know each other's decision of fertilisation, and the buyer knows the same crop production information of farmer A and farmer B. If both party A and party B choose to implement plan A, the benefits of both parties will be the same as that of the same choice in (1). If party A chooses plan A and party B chooses plan B, the sales volume of party A and party B in the market does not change because the buyers do not know the specific information of both parties. However, because B chooses plan B and applies excessive amount of fertiliser, the crop 
yield increases, and the unit fertiliser cost of B decreases to $c$. At this time, the income of A and $\mathrm{B}$ is $Q_{1}\left(P_{1}-C\right)$ and $Q_{2}\left(P_{2}-C\right)$ respectively. If both party A and party B choose plan B at the same time, their sales volume remains unchanged, and the unit fertiliser cost changes to $c$ at the same time. At this time, both parties gain $Q_{1}\left(P_{1}-c\right)$ and $Q_{2}\left(P_{2}-c\right)$ respectively. The game payoff matrix of farmer $\mathrm{A}$ and farmer $\mathrm{B}$ under the condition of complete non-disclosure of information is shown in Table 3.

Through the game payoff matrix analysis of party A and party $\mathrm{B}$, it can be seen that when party A and party B choose plan B at the same time, the cost of both parties decreases and the profit increases, reaching Nash equilibrium. At this time, both sides choose to apply excessive amount of chemical fertiliser, which increases crop yield and aggravates non-point source pollution of chemical fertiliser, and can be effectively controlled.

(3) Game analysis of farmer's fertilisation behaviour under the condition of incomplete information.

For the complete information and information described in (1) and (2), the two conditions are completely unrealised. Under actual conditions, it is difficult to achieve the situation. Under the condition of incomplete information, the farmers guess each other's fertilisation behaviour and make their own judgment according to the judgment. Decision-making, if the farmers only make a decision together with each other, then the income matrix is the same as the result in (2), and the over-fertilisation must be selected at the same time. But in the actual situation, not only the game behaviour is performed between the farmers in the process. Assume that the secondary game between the A and B farmers, the impact of each game on the sales volume of agricultural products is $T_{\mathrm{n}}$. If both sides adopt excessive fertilisation, the final unit crop fertilisation cost is still $c$, and its corresponding game payoff matrix is shown in Table 4.

Table 4

Game payoff matrix under incomplete information conditions

\begin{tabular}{|c|c|c|c|}
\hline \multicolumn{2}{|c|}{$\begin{array}{c}\text { Participate in farmers and } \\
\text { options }\end{array}$} & \multicolumn{2}{|c|}{ Party B } \\
\cline { 2 - 4 } & \multirow{4}{*}{ Option A } & $Q_{1}\left(P_{1}-C\right), Q_{2}\left(P_{2}-c\right)$ & $\begin{array}{c}\left(Q_{1}+T_{1}+\ldots+T_{\mathrm{n}}\right)\left(P_{1}-C\right), \\
\left(Q_{2}-T_{1}-\ldots-T_{\mathrm{n}}\right)\left(P_{2}-c\right)\end{array}$ \\
\cline { 2 - 4 } & Option B & $\begin{array}{c}\left(Q_{1}-T_{1}-\ldots-T_{\mathrm{n}}\right)\left(P_{1}-c\right), \\
\left(Q_{2}+T_{1}+\ldots+T_{\mathrm{n}}\right)\left(P_{2}-C\right)\end{array}$ & $\begin{array}{c}\left(Q_{1}-T_{1}-\ldots-T_{\mathrm{n}}\right)\left(P_{1}-c\right), \\
\left(Q_{2}-T_{1}-\ldots-T_{\mathrm{n}}\right)\left(P_{2}-c\right)\end{array}$ \\
\hline
\end{tabular}

According to the Nash equilibrium, the two behaviour choices are first excluded, (Farmer A environmentally friendly fertilisation, Farmer B environmental pollution fertilisation) and (Farmer A environmental pollution fertilisation, Farmer B environmentally friendly fertilisation). In the case of choosing environmentally friendly fertilisation or environmental pollution fertilisation at the same time, because the profit and sales volume change in the opposite direction, the results cannot be compared. However, with the increase in the number of games between the two parties, more information will be disclosed. In order to protect their own economic interests and seek stability, farmers will be more inclined to choose environmentally friendly fertilisation at the same time.

Through the above game analysis, it can be known that the degree of information disclosure affects the choice of farmers' fertilisation behaviours. The higher the degree of information disclosure is, the more favorable it is to the control of non-point source pollution. However, information disclosure usually needs to be assisted by government agencies and social organizations. Farmers are the main cause of non-point source pollution 
of fertilisers. Farmers' behaviour is the key to controlling non-point source pollution of chemical fertilisers. How to coordinate the behaviours of the governments, farmers and fertiliser sellers in all aspects of pollution control is the main content of this paper.

\section{Fertiliser sellers' behaviour}

The weak nature of China's agriculture is very obvious. In the process of planting and production by farmers, the purchase of chemical fertiliser is an important part. The fertiliser sellers, as the main body that can directly contact farmers and affect the purchase of chemical fertilisers by farmers, are in the pollution control of chemical fertilisers. The role can not be ignored. Fertiliser sellers can directly contact farmers when they purchase fertiliser products, which has a certain guiding effect on the purchase behaviour of farmers. Under normal circumstances, the cultural level of farmers is not high, the knowledge of chemical fertilisers is insufficient, and the information between fertiliser sellers is not equal, and the competition in agricultural products market is fierce. It is highly probable that fertiliser sellers will maximise their own interests. Inductive purchase behaviour, and thus inappropriate fertiliser application will inevitably increase the non-point source pollution of fertiliser. On the other hand, the government advocates protection, improvement of the agricultural production environment, and construction of a benign agricultural product sales environment. If the government supplements economic incentives to encourage fertiliser sellers to sell environmentally friendly fertilisers, it will increase the sales of chemical fertilisers. The possibility of fertilisers. Farmers as a customer group of fertiliser sellers, when farmers are willing to increase the demand for environmentally friendly fertilisers, fertiliser sellers in order to attract the attention of farmers, increase sales and increase their income, will inevitably follow the market. The demand situation changes its own sales behaviour, increasing the possibility that fertiliser sellers choose to sell environmentally friendly fertilisers.

\section{The comprehensive behaviour relationship of the three parties}

Theoretically, assuming that governments, farmers, and fertiliser sellers are all rational economic agents, government supervision of farmers' fertilisation behaviour will have a direct impact on the control effect of chemical fertiliser non-point source pollution. But from a practical perspective, the government directly supervises the fertilisation behaviour of farmers. There are too many restrictions on the fertilisation behaviour, which is difficult to achieve. For example, the human, material and financial resources required for government supervision are too high, and the effects of pollution control cannot be guaranteed. Therefore, the government can directly regulate the fertilisation behaviour of farmers to entrust fertiliser dealers to indirectly supervise the fertilisation behaviour of farmers, and directly supervise the sales behaviour of fertiliser sellers, with appropriate policy measures, in order to maximise the balance of interests of the three parties and achieve effective management of non-point source pollution of chemical fertilisers, improvement of agricultural production environment, and promotion of sustainable agricultural development [18, 19]. In this governance system, the three parties are stakeholders, the regulatory role of governments promotes the transformation of farmers into environmentally friendly fertilisation behaviours, and supervises the sales of chemical fertilisers by fertiliser sellers. If farmers and fertiliser sellers choose environmentally friendly, the behaviour promotes the pollution control of non-point source pollution in the 
province, improves the overall welfare of the society, and the government's own interests are satisfied. The relationship between the interests of the three parties is shown in Figure 3.

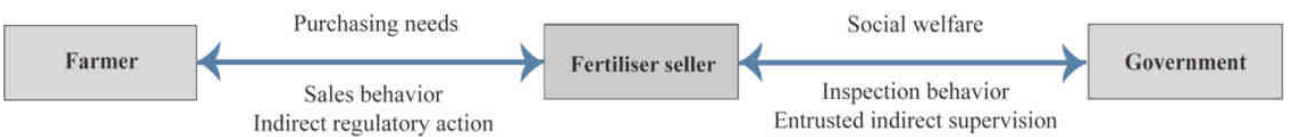

Fig. 3. The relationship between the interests of the three parties

\section{Game model of tripartite subject behaviour}

\section{Static game model with complete information}

A complete information static game model with the participation of the government, farmers and chemical fertiliser dealers is established. The basic assumptions are as follows:

(1) Suppose that the provincial government, farmers and chemical fertiliser dealers are the three main bodies of the complete rational economic man.

(2) The decision-making choices of the tripartite subjects are clear to each other.

(3) The government shall have the right to decide whether the chemical fertiliser dealer has the right to inspect or not to inspect whether or not there is a violation of the sales behaviour of the chemical fertiliser dealer. Government inspections are recorded as $C$. The government gives financial incentives to regular chemical fertiliser dealers as $S_{1}$. The government imposes financial penalties on irregular chemical fertiliser dealers and fines are recorded as $T$.

(4) The income earned by chemical fertiliser dealers in accordance with the prescribed sales of chemical fertilisers is recorded as $R_{0}$, and the cost of maintaining this sales model is $C_{0}$. The income earned by chemical fertiliser dealers from illegal sales of chemical fertilisers is recorded as $R^{\prime}$, the cost of maintaining this sales model is $C^{\prime}$, at the same time $\left(R^{\prime}-C^{\prime}\right)>\left(R_{0}-C_{0}\right)$.

(5) When farmers accept the purchase of environmentally friendly chemical fertilisers, the agricultural production income is recorded as $R_{1}$. When farmers accept the purchase of environmentally polluting fertilisers, the agricultural production income is recorded as $R_{2}$. If farmers refuse to buy any kind of chemical fertiliser, the income is 0 . Under the premise that the government inspects the sales behaviour of chemical fertiliser dealers, farmers buy environmentally friendly chemical fertilisers, and the government entrusts chemical fertiliser dealers to give farmers economic subsidies $S_{2}$.

Profit matrix of mixed strategy game of three parties

Table 5

\begin{tabular}{|c|c|c|c|c|}
\hline \multirow{2}{*}{} & \multicolumn{2}{|c|}{$\begin{array}{c}\text { Fertiliser dealers sell according to } \\
\text { regulations }(\boldsymbol{q})\end{array}$} & \multicolumn{2}{c|}{$\begin{array}{c}\text { Illegal sales of fertiliser dealers } \\
(\mathbf{1}-\boldsymbol{q})\end{array}$} \\
\cline { 2 - 5 } & $\begin{array}{c}\text { Farmers accept } \\
\text { purchase }(\boldsymbol{r})\end{array}$ & $\begin{array}{c}\text { Farmers refuse to } \\
\text { buy }(\mathbf{1}-\boldsymbol{r})\end{array}$ & $\begin{array}{c}\text { Farmers accept } \\
\text { purchase }(\boldsymbol{r})\end{array}$ & $\begin{array}{c}\text { Farmers refuse } \\
\text { to buy }(\mathbf{1}-\boldsymbol{r})\end{array}$ \\
\hline Government & $R_{0}-C_{0}+S_{1}$ & $C_{0}+S_{1}$ & $R^{\prime}-C^{\prime}-T$ & $-C^{\prime}-T$ \\
inspection & $R_{1}+S_{2}$ & 0 & $R_{2}$ & 0 \\
$(p)$ & $-C-S_{1}-S_{2}$ & $-C-S_{1}$ & $-C+T+H-L$ & $-C+T+H$ \\
\hline The government & $R_{0}-C_{0}$ & $-C_{0}$ & $R^{\prime}-C^{\prime}$ & $-C^{\prime}$ \\
doesn't check & $R_{1}$ & 0 & $R_{2}$ & 0 \\
$(1-p)$ & 0 & 0 & $-h-L$ & 0 \\
\hline
\end{tabular}


(6) Government chooses to inspect fertiliser dealers' sales behaviour to increase social welfare gains, denoted by $H$. The government chose not to check the negative externalities of the fertiliser dealer's selling behaviour, denoted by $h$.

(7) The loss of social welfare caused by farmers' choice of environmental pollution chemical fertiliser is recorded as $L$.

The probability of provincial government choosing to check the sales behaviour of chemical fertiliser dealers is $p,(0 \leq p \leq 1)$, the probability of chemical fertiliser dealers selling chemical fertiliser according to the regulations is $q,(0 \leq q \leq 1)$, and the probability of farmers choosing to accept purchase is $r,(0 \leq r \leq 1)$. The mixed strategy game payoff matrix of the tripartite main body is shown in Table 5 .

The government's expected income function $U_{p}$ :

$$
\begin{gathered}
U_{p}=p q r\left(-C-S_{1}-S_{2}\right)+p q(1-r)\left(-C-S_{1}\right)+p(1-q) r(-C+T+H-L) \\
+p(1-q)(1-r)(-C+T+H)+(1-p)(1-q) r(-h-L)
\end{gathered}
$$

Expected revenue function of fertiliser distributor $U_{q}$ :

$$
\begin{gathered}
U_{q}=p q r\left(R_{0}-C_{0}+S_{1}\right)+p q(1-r)\left(-C_{0}+S_{1}\right)+p(1-q) r\left(R^{\prime}-C^{\prime}-T\right) \\
+(1-p) q r\left(R_{0}-C_{0}\right)+(1-p) q(1-r)\left(-C_{0}\right)+(1-p)(1-q) r\left(R^{\prime}-C^{\prime}\right) \\
+(1-p)(1-q)(1-r)\left(-C^{\prime}\right)
\end{gathered}
$$

Farmer's expected income function $U_{r}$ :

$$
U_{r}=p q r\left(R_{1}+S_{2}\right)+p(1-q) r R_{2}+(1-p) q r R_{1}+(1-p)(1-q) r R_{2}
$$

According to the existence theorem of Nash equilibrium, the mixed strategy Nash equilibrium is derived from the extremum of the expected payoff function of the three parties [20].

$$
\left\{\begin{array}{c}
\frac{\partial U_{p}}{\partial p}=-q^{*} r^{*}\left(S_{2}+h\right)-q^{*}\left(S_{1}+T+H\right)+r^{*} h+T+H-C=0 \\
\frac{\partial U_{q}}{\partial q}=p^{*}\left(T+S_{1}\right)+r^{*}\left(R_{0}-R^{\prime}\right)+C^{\prime}-C_{0}=0 \\
\frac{\partial U_{r}}{\partial r}=p^{*} q^{*} S_{2}+q^{*}\left(R_{1}-R_{2}\right)+R_{2}=0
\end{array}\right.
$$

According to the equations set, the result is:

$$
\left\{\begin{array}{c}
p^{*}=\frac{q^{*}\left(R_{2}-R_{1}\right)-R_{2}}{q^{*} S_{2}} \\
q^{*}=\frac{r^{*} h+T+H-C}{r^{*}\left(S_{2}+h\right)+S_{1}+T+H} \\
r^{*}=\frac{p^{*}\left(T+S_{1}\right)+C^{\prime}-C_{0}}{R^{\prime}-R_{0}}
\end{array}\right.
$$

From this, we get the mixed strategy Nash equilibrium solution of the static game of complete information between the government, farmers and chemical fertiliser dealers, that is (Government: $\left(p^{*}, 1-p^{*}\right)$, Fertiliser Dealers: $\left(q^{*}, 1-q^{*}\right)$, Farmers: $\left.\left(r^{*}, 1-r^{*}\right)\right)$. The results show that the mixed strategy Nash equilibrium of the static game of complete information between the government, farmers and chemical fertiliser dealers cannot obviously show the direct impact of the behaviour of the tripartite main body on the control 
of chemical fertiliser non-point source pollution, so this paper chooses the incomplete information dynamic game model for in-depth study.

\section{Dynamic game model with incomplete information}

In the context of the actual social environment, the behavioural information between the governments, farmers and fertiliser sellers cannot reach a state of complete mutual understanding. Each subject knows the strategic space of other subjects, but cannot determine what strategies other subjects make select [21]. Establish a dynamic game model of incomplete information involving governments, farmers and fertiliser sellers. The basic assumptions are as follows:

(1) The three main bodies of government, farmers and fertiliser distributors are completely rational economic persons.

(2) The Government's choice is to inspect or not to inspect the sales activities of the fertiliser distributor. The behaviour of the fertiliser distributor shall be that the environmentally friendly chemical fertiliser is sold in accordance with the provisions or that the environmental pollution chemical fertiliser is sold in violation of the provisions. The farmer's behaviour choice is to accept to buy or refuse to buy the by the fertiliser seller. Government, farmers and fertiliser distributors know each other's strategy space, but they do not know each other's behaviour choice.

(3) The profit obtained by the fertiliser sellers who choose to sell environmentally friendly fertilisers according to the regulations is recorded as $W$, and the cost of sales is recorded as $C_{0}$. The profit obtained by illegally selling environmentally polluting fertilisers is increased by $W^{\prime}, W^{\prime}>0$, at this time, the cost of sales is $t \cdot C_{0}, 0<t<1$. When the government checks that the fertiliser seller has violated the sales behaviour, the fertiliser seller is ordered to rectify and impose economic punishment, and the amount of the fine is recorded as $T$. Governing the illegal sales of fertiliser sellers has improved the sales environment of fertilisers and agricultural products, bringing positive effects to the society as a whole, and the increase in social welfare income is $H$.

(4) The cost required by the government to inspect the fertiliser sellers is recorded as $C$. If the fertiliser sellers are found to sell environmentally friendly fertilisers as required, or the farmers accept the purchase of environmentally friendly fertilisers, the government will for economic incentives, the total amount is recorded as $S$, in which the amount of incentives for fertiliser sellers is $m \cdot S$, and the amount of subsidies for farmers is $(1-m) \cdot S$, where $0<m<1$.

(5) Farmers choose to accept the economic benefits $R$ that can be obtained by purchasing environmentally friendly fertilisers. The economic benefits that farmers can choose to receive environmentally polluting fertilisers are $n \cdot R$, where $n>1$. Farmers need to control fertiliser sources, the cost is $k \cdot C$.

(6) If the farmer chooses to accept environmental pollution-type fertiliser, it will bring about non-point source pollution of chemical fertiliser. The characteristics of chemical fertiliser non-point source pollution can be known to cause social welfare losses, which is recorded as $L$. Assume that farmers do not check the sales of fertiliser sellers in the government. In the case of behaviour, the default is to be environmentally friendly.

(7) The probability that a fertiliser seller chooses to sell environmentally friendly fertilisers according to regulations is $p$, and the probability of illegally selling environmentally polluting fertilisers is $(1-p)$. The probability that governments choose to check whether the sales behaviour of fertiliser sellers is compliant is $q$, the probability of 
choosing not to check the behaviour is $(1-q)$. The probability that the farmer chooses to accept the fertiliser product of the fertiliser seller is $r$, then the probability of refusing the purchase behaviour is $(1-r)$.

Through the above basic assumptions, a behavioural game decision tree for fertiliser sellers, governments, and farmers can be established. As shown in Figure 4, the benefits of the three parties under the eight strategy combinations are shown in Table 6.

Table 6

Eight strategies combined income statement

\begin{tabular}{|c|c|c|c|c|}
\hline $\begin{array}{c}\text { Strategic } \\
\text { combination }\end{array}$ & $\begin{array}{c}\text { Fertiliser seller } \\
\text { revenue }\end{array}$ & $\begin{array}{c}\text { Government } \\
\text { revenue }\end{array}$ & $\begin{array}{c}\text { Farmer } \\
\text { income }\end{array}$ & Combined probability \\
\hline Situation 1 & $W+m \cdot S$ & $-C-S$ & $R+(1-m) \cdot S$ & $p \cdot q \cdot r$ \\
\hline Situation 2 & $-C_{0}+m \cdot S$ & $-C-m \cdot S$ & 0 & $p \cdot q \cdot(1-r)$ \\
\hline Situation 3 & $W$ & 0 & $R$ & $p \cdot(1-q) \cdot r$ \\
\hline Situation 4 & $-C_{0}$ & 0 & 0 & $p \cdot(1-q) \cdot(1-r)$ \\
\hline Situation 5 & $W+W-T$ & $-C+T+H-L$ & $n \cdot R-k \cdot C$ & $(1-p) \cdot q \cdot r$ \\
\hline Situation 6 & $-t \cdot C_{0}-T$ & $-C+T+H$ & 0 & $(1-p) \cdot q \cdot(1-r)$ \\
\hline Situation 7 & $W+W$ & $-L$ & $n \cdot R$ & $(1-p) \cdot(1-q) \cdot r$ \\
\hline Situation 8 & $-t \cdot C_{0}$ & 0 & 0 & $(1-p) \cdot(1-q) \cdot(1-r)$ \\
\hline
\end{tabular}

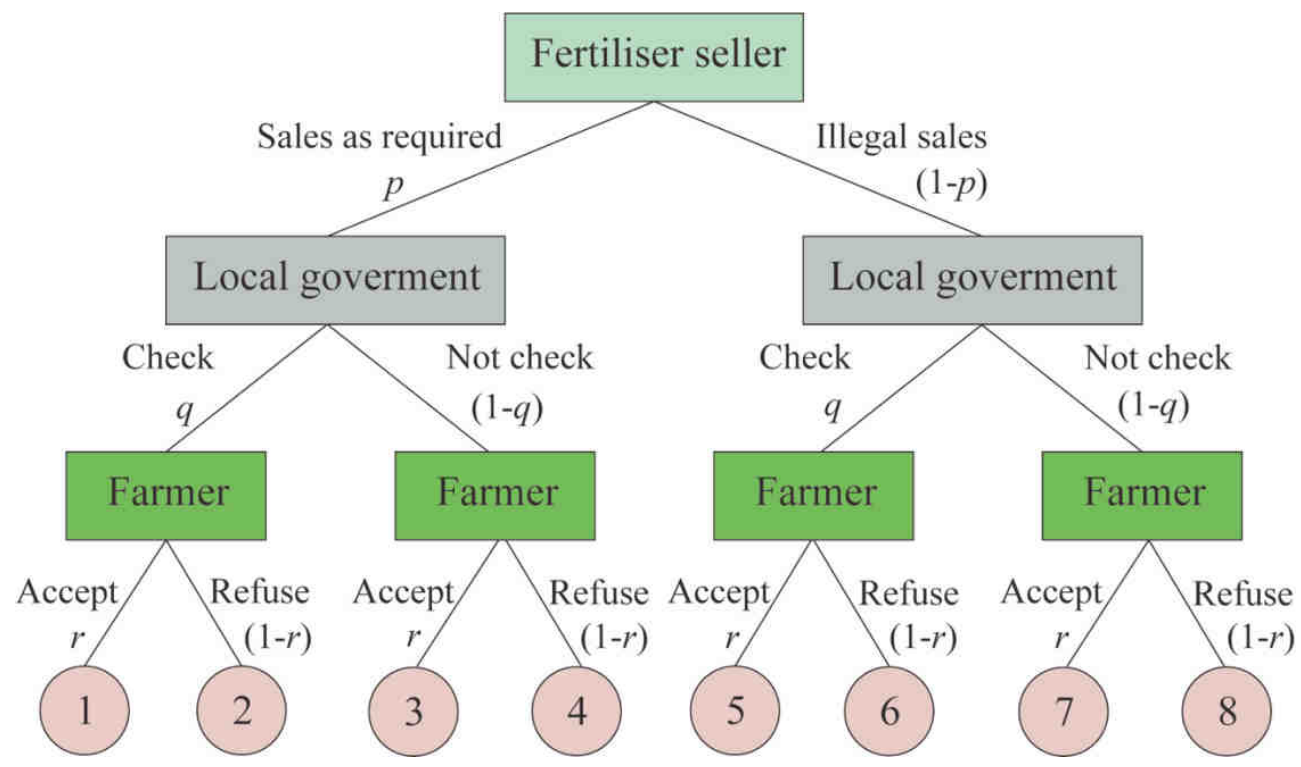

Fig. 4. Tripartite subject behaviour game decision tree

According to Haysani Axiom, the incomplete information dynamic game model of the government, farmers and fertiliser sellers can be converted into a complete but imperfect information dynamic game model. According to the game decision tree of the three parties and different strategies. The income, respectively, derives the expected return function of the three parties, and then finds the equilibrium solution of the three-party game [22, 23]. 
Fertiliser seller's expected return function:

$$
\begin{gathered}
U_{p}=p q r(W+m S)+p q(1-r)\left(-C_{0}+m S\right)+p(1-q) r W \\
+p(1-q)(1-r)\left(-C_{0}\right)+(1-p) q r\left(W+W^{\prime}-T\right)+(1-p) q(1-r)\left(-t C_{0}-T\right) \\
+(1-p)(1-q) r\left(W+W^{\prime}\right)+(1-p)(1-q)(1-r)\left(-t C_{0}\right)
\end{gathered}
$$

To find the first-order partial derivative of $p$, we can get the equilibrium solution as:

$$
\begin{gathered}
\frac{\partial U_{p}}{\partial p}=q(m S+T)+r\left[(1-t) C_{0}-W^{\prime}\right]+(t-1) C_{0}=0 \\
r=\frac{q(m S+T)-(1-t) C_{0}}{W^{\prime}-(1-t) C_{0}}
\end{gathered}
$$

Assuming that the government checks the sales behaviour of the fertiliser seller, formula (8) becomes:

$$
r=\frac{m S+T-(1-t) C_{0}}{W^{\prime}-(1-t) C_{0}}
$$

According to the analysis of formula (9), when the government chooses to check the sales behaviour of the fertiliser seller, the farmer chooses the probability of purchasing the fertiliser and the government's reward and punishment for the sales behaviour of the fertiliser seller, $m \cdot S$ and $T$, and the fertiliser seller according to regulations. The profit of selling environmentally friendly fertilisers is related to the cost of chemical fertilisers $(1-t) \cdot C_{0}$. When the fertiliser sellers sell the profits according to the regulations and the cost of illegal sales, the government will increase the incentives for the fertiliser sales to choose different economic sales, and the greater the willingness of farmers to accept the purchase.

The government's expected return function:

$$
\begin{gathered}
U_{q}=p q r(-C-S)+p q(1-r)(-C-m S)+(1-p) q r(-C+T+H-L) \\
+(1-p) q(1-r)(-C+T+H)+(1-p)(1-q) r(-L)
\end{gathered}
$$

To find the first-order partial derivative of $q$, we can get the equilibrium solution as:

$$
p=\frac{T+H-C}{r(1-m) S+m S+T+H}
$$

To simplify the analysis, assume that farmers have the same possibility of accepting and refusing to purchase fertilisers:

$$
p=\frac{T+H-C}{0.5(1+m) S+T+H}
$$

When farmers choose random purchase behaviours, the probability of chemical fertiliser sellers selling fertiliser according to the regulations is closely related to the economic incentive strength $S$ of the government to the behaviour choice of farmers and chemical fertiliser sellers, the inspection cost $C$ of the sales behaviour of chemical fertiliser sellers by the government and the punishment strength $T$ of illegal sales behaviour, and the social welfare income $H$ brought about by the control of illegal sales behaviour. In the case that the government's economic incentives and punishment policies are determined and the social welfare brought by the illegal sales behaviour is fixed, the higher the cost required by the government to check the sales behaviour of the fertiliser sellers, the fertiliser sellers 
think from the perspective of rational economic people. The inspection behaviour of governments believes that the cost of inspection is too high, and the probability of inspection behaviour is very small. In order to obtain high profits brought by illegal sales, the probability that fertiliser sellers choose to sell environmentally friendly fertilisers according to regulations is smaller.

The expected income function of the farmer is:

$$
\begin{gathered}
U_{r}=\operatorname{pqr}[R+(1-m) S]+p(1-q) r R+(1-p) q r(n R-k C) \\
+(1-p)(1-q) r n R
\end{gathered}
$$

Find the first partial derivative of $r$, we can get the equilibrium solution as:

$$
q=\frac{(n+p-n p) R}{(1-p) k C-p(1-m) S}
$$

For the convenience of analysis, it is assumed that the probability of compliance and violation of the sales of chemical fertilisers by fertiliser sellers is equal:

$$
q=\frac{(1+n) R}{k C-(1-m) S}
$$

According to the analysis of this result, the inspection probability of the government to the fertiliser seller is determined by the sum of the economic benefits of the farmers under the two kinds of fertiliser behaviour divided by the cost required by the farmers to control the fertiliser non-point source pollution by the government minus the economic subsidy of the farmers who choose the environmentally friendly fertiliser behaviour.

From the above research and analysis, it can be seen that the decisions made by the government, fertiliser sellers and farmers in the behaviour selection stage have a great influence on the choice of the other two subjects. The process of the three parties' strategy selection is three-way. The process of dynamic gaming. In the context of the actual social environment, it is difficult for the three parties to achieve a completely rational economic person. Under the limited conditions, the three parties are all bounded rational economic agents. At the same time, the economic benefits of fertiliser sellers and farmers are affected by many external factors. For example, the production income of farmers is not only determined by fertilisation behaviour, the natural climatic conditions of crops, etc. will directly affect the income of farmers. The government acts as a third-party social organization and serves as the regulatory organization in the province's chemical fertiliser non-point source pollution control system. Compared with the other two subjects, the flexibility of behaviour change is very small. Reasonable formulation of laws, regulations and policies related to the behaviour of the three parties directly affects the results of strategic choices of the subjects, which can promote the choice of benevolent behaviours of the three parties. The policies it introduces closely related to the economic interests of the fertiliser sellers and farmers, which in turn determines whether the fertilisation behaviour of farmers is aggravating the non-point source pollution of fertilisers or making the non-point source pollution of fertilisers effectively treated.

\section{Conclusion and discussion}

When the behaviour of the tripartite subject is chosen, it is limited to a great extent by its own behaviour cost, income and the influence of the external reward and punishment system. Because of its own nature, the government plays an important role in the control of 
chemical fertiliser non-point source pollution in province. According to the equilibrium solution of mixed strategy to solve the dynamic game model of incomplete information according to Haysani Axiom transformation, it can be seen that due to the limitation of chemical fertiliser sellers and farmers' own conditions, the behaviour choice of government and its role of authority play a very important role in the behaviour choice of farmers and chemical fertiliser sellers. The proper choice of the behaviour of the government or the introduction of appropriate laws, regulations and policies by the government will promote the effective control of chemical fertiliser non-point source pollution. The regulatory costs of governments, financial subsidies and fines, farmers' own income, chemical fertiliser dealers' sales costs and benefits and other factors may change the behaviour strategy choice of each subject. Among them, because the government as a regulatory organization, and has a strong controllability, improving the control effect of chemical fertiliser non-point source pollution through the behaviour of the government is the most economical and effective method at this stage. According to the characteristics of the work of the government, the following four countermeasures and suggestions are put forward.

(1) Increase investment in funds

As the regulator of economic activities in the province, the government plays a very important role in its functions and powers. By increasing investment to achieve economic means to prevent non-point pollution, non-point source pollution control and new technology research and development to provide economic incentives subsidies, vigorously support the pollution prevention and control of scientific and technological research and promotion [24]. After increasing the intensity of capital investment, also should reasonably arrange special funds as a whole, make clear the direction and quantity of capital flow, make special funds special, ensure the practical application of funds in the control of chemical fertiliser non-point source pollution, and ensure the smooth progress of chemical fertiliser non-point source pollution control work.

(2) To improve the standards of chemical fertiliser related personnel

Improve the standards of chemical fertiliser related workers; improve the overall quality of chemical fertiliser related working environment. For those who want to engage in chemical fertiliser related work, such as chemical fertiliser professional knowledge announcer, chemical fertiliser product salesman, etc., the relevant work units may provide teaching and training, and then the government can carry out unified professional knowledge and skills test, and only after passing, chemical fertiliser related work can be allowed. This can ensure that farmers receive the correct chemical fertiliser application knowledge and avoid farmers mishearing and misbelieving others. This promotes the continuous optimization of the fertiliser working environment and the rational application of chemical fertiliser to reduce the non-point source pollution of chemical fertilisers.

(3) Implementation of regulatory facilities

"Internet+" modern agriculture is the inevitable trend of future development. In order to better control and control non-point source pollution of chemical fertilisers, advanced information technology should be used to develop farmers' fertiliser behaviour supervision facilities. For example, by comparing the content of chemical elements in land with the standard content at any time that can master the changing trend of chemical fertiliser non-point source pollution in province. If there is a large data gap, the specific fertiliser application should be verified in time. Find out the causes and put forward the corresponding control measures to improve the ability to deal with chemical fertiliser non-point source pollution. 
(4) Realising the legitimate rights of farmers

Before the government and relevant departments formulate new policies and regulations, should hold seminars with the participation of farmers, listen to the ideas of farmers, master the actual needs of farmers, and enhance the implementation of government policies. Under the premise that the government supervises the choice behaviour of chemical fertiliser dealers and farmers, in order to ensure the legal compliance of the provincial government in the use of its functions and powers, the government behaviour anti-supervision department should be set up. Chemical fertiliser dealers and farmers can put forward reasonable suggestions to the provincial government or report to the provincial government and relevant departments on illegal supervision and operation, so as to maintain the benign operation of chemical fertiliser non-point source pollution control environment. At the same time, note that when chemical fertiliser dealers or farmers choose to realise their right to participate in decision-making, should ensure that their main recommendations or reports enjoy immunity from responsibility, so as not to reduce the enthusiasm of both parties to participate in the control of chemical fertiliser non-point source pollution.

\section{Acknowledgements}

National Natural Science Foundation Project: Farmers' behaviour of fertiliser application and agricultural non-point source pollution control: impact mechanism and policy simulation research (71573036). National Social Science Fund: Research on the coupling of blockchain technology and agricultural ecological products supply chain governance (20FGLB059).

\section{References}

[1] Bo S, Zhang L, Yang L, Zhang L, David N, Zhu Z. Agricultural non-point source pollution in China: causes and mitigation measures. Ambio. 2012;41(4):370-9. DOI: 10.1007/s13280-012-0249-6.

[2] Wu H, Ge Y. Excessive application of fertilizer, agricultural non-point source pollution, and farmers' policy choice. Sustainability. 2019;11(4):1165. DOI: 10.3390/su11041165.

[3] Cho M, Jang T, Jang JR, Yoon CG. Development of agricultural non-point source pollution reduction measures in Korea. Irrigation Drainage. 2016;65:94-101. DOI: 10.1002/ird.1993.

[4] Ahmad Z. Metals uptake by wastewater irrigated vegetables and their daily dietary intake in Peshawar, Pakistan. Ecol Chem Eng S. 2015;22(1):125-39. DOI: 10.1515/eces-2015-0008.

[5] Marszałek M, Kowalski Z, Makara A. The possibility of contamination of water-soil environment as a result of the use of pig slurry. Ecol Chem Eng S. 2019;26(2):313-30. DOI: 10.1515/eces-2019-0022.

[6] Wang Y, Yang J, Liang J, Qiang Y, Fang S, Gao M, et al. Analysis of the environmental behavior of farmers for non-point source pollution control and management in a water source protection area in China. Sci Total Environ. 2018;633:1126-35. DOI: 10.1177/0954407012475272.

[7] Grazhdani D. Contingent valuation of residents' attitudes and willingness-to-pay for non-point source pollution control: a case study in AL-Prespa, Southeastern Albania. Environ Manage. 2015;56(1):81-93. DOI: $10.1007 / \mathrm{s} 00267-015-0480-6$.

[8] Zhang T, Ni J, Xie D. Assessment of the relationship between rural non-point source pollution and economic development in the Three Gorges Reservoir Area. Environ Sci Pollut Res. 2016;23(8):8125-32. DOI: 10.1007/s11356-016-6344-7.

[9] Abler D. Economic evaluation of agricultural pollution control options for China. J Integrative Agricult. 2015;14(6):1045-56. DOI: 10.1016/S2095-3119(14)60988-6.

[10] Rissman AR, Carpenter SR. Progress on nonpoint pollution: barriers \& opportunities. Daedalus. 2015;144(3):35-47. DOI: 10.1162/DAED_a_00340.

[11] Portney PR. Public policies for environmental protection. Routledge. 2016:178-98. DOI: $10.4324 / 9781315651477$. 
[12] Cultivated land area of all countries in the world in 2017. Available from: https://data.worldbank.org.cn/indicator/AG.LND.ARBL.HA?end=2018\&name_desc=true\&start=2018\&vie $\mathrm{w}=$ map \&year $=2017$.

[13] Application amount of chemical fertilizer in the world in 2017. Available from: http://www.fao.org/faostat/en/\#data.

[14] Fertilizer application in China from 2013 to 2019. Available from: https://data.stats.gov.cn/easyquery.htm?cn=C01\&zb=A0D06\&sj=2019.

[15] Dahan NM, Doh JP, Raelin JD. Pivoting the role of government in the business and society interface: A stakeholder perspective. J Business Ethics. 2015;131(3):665-80. DOI: 10.1007/s10551-014-2297-2.

[16] Zhang M, Li H, Xue L, Wang W. Using three-sided dynamic game model to study regional cooperative governance of haze pollution in China from a government heterogeneity perspective. Sci Total Environ. 2019;694:133559. DOI: 10.1016/j.scitotenv.2019.07.365.

[17] Başar T, Olsder GJ. Dynamic Noncooperative Game Theory. Society for Industrial and Applied Mathematics. 1998;95-116. ISBN: 9780898714296.

[18] Key S. Toward a new theory of the firm: a critique of stakeholder "theory". Manage Decision. 1999;37(4):317-28. DOI: 10.1108/00251749910269366.

[19] Blair MM. For whom should corporations be run? An economic rationale for stakeholder management. Long Range Planning. 1998; 31(2):195-200. DOI: 10.1016/S0024-6301(98)00003-X.

[20] Vives X. Nash equilibrium with strategic complementarities. J Mathematical Economics. 1990;19(3):305-21. DOI: 10.1016/0304-4068(90)90005-T.

[21] Rothschild M, Stiglitz J. Equilibrium in competitive insurance markets an essay in the economics of incomplete information. Quarterly J Economics. 1976;90:629-49. DOI: 10.2307/1885326.

[22] Harsanyi JC. A bargaining model for cooperative n-Person games. Annals Mathematics Studies. 1959;40:325-55. DOI: 10.1515/9781400882168-019.

[23] Harsanyi JC. A General Solution for Finite Noncooperative Games Based on Risk-Dominance. Advances in Game Theory. Princeton University Press. 2016;52:651-80. DOI: 10.1515/9781400882014-030.

[24] Sołowski G, Konkol I, Cenian A. Perspectives of hydrogen production from corn wastes in Poland by means of dark fermentation. Ecol Chem Eng S. 2019;26(2):255-63. DOI: 10.1515/eces-2019-0031. 